\title{
Synthesis and electron-donating properties of novel norphthalocyanines containing thiacrown ether-linked tetrathiafulvalene moieties
}

\author{
Jia Guo ${ }^{\mathrm{a}, \mathrm{b}}$, Yan Xia ${ }^{\mathrm{a}}$, Dongfeng $\mathrm{Li}^{\mathrm{a}, *}$, Ruibin $\mathrm{Hou}^{\mathrm{a}, \mathrm{b}, *}$ \\ ${ }^{a}$ School of Chemistry and Life Science, Changchun University of Technology, Changchun, 130012, China \\ ${ }^{b}$ Advanced Institute of Materials Science, Changchun University of Technology, Changchun 130012, China
}

\begin{abstract}
A novel magnesium-base and metal-free norphthalocyanine (6 and 7) containing a peripheral thiacrown ether-linked tetrathiafulvalene moieties has been synthesized and fully characterized. Electrochemical investigations showed two quasi-reversible one-electron oxidation waves, one irreversible one-electron oxidation wave and two irreversible one-electron reduction waves, indicating that these triads are good $\pi$-electron donors. Triad $\mathbf{6}$ reacted with 2,3,5,6-tetrafluoro-7,7,8,8-tetra-cyanoquinodimethane $\left(\mathrm{F}_{4} \mathrm{TCNQ}\right)$ to form a charge transfer complex that exhibited absorption bands in the vicinty of 750 and $960 \mathrm{~nm}$. Compound 6 showed evident intramolecular charge transfer interactions in ground states and these may be explained on the basis of density functional theory.
\end{abstract}

Keywords: norphthalocyanine; tetrathiafulvalene; crown ether; density functional theory

\section{subtitles : Synthesis and properties of the conjugates of norphthalocyanines and tetrathiafulvalene}

\footnotetext{
*Corresponding author. Tel: +86 431 85716671, Fax: +86 431 85910726, E-mail address: hrb1018@163.com（R.B.Hou）
} 
The construction of ensembles composed of covalently linked electron donor and acceptor moieties is currently a significant challenge in the field of material science and supramolecular chemistry. ${ }^{1-7}$ Typical examples of this type of ensemble are the polyads derived from tetrathiafulvalene (TTF) derivatives and macrocyclic tetrapyrroles (porphyrin, phthalocyanine and porphyrazine) ${ }^{8-10}$ To date, a wide variety of symmetrical macrocyclic tetrapyrroles have been extensively studied. ${ }^{11-13}$ However, there have been only a limited number of reports on concerning unsymmetrical porphyrinic macrocycles, ${ }^{14-17}$ mainly because they are much more difficult to be synthesized and purified. In recent years, there has been a growing interest in the properties of the unsymmetrical phthalocyanines (Pcs) because these compounds display high thermal stability, mesogenic behavior, and second- or third-order nonlinear optical properties in solution, and are also capable of forming Langmuir-Blodgett films exhibiting semiconducting properties. Recently, we reported a series of symmetrical porphyrazines (Pzs) bearing tetrathiafulvalene (TTF) units, including the Pzs linked with TTF units containing either crown ether or ethylenedithio spacers. ${ }^{18}$ Pzs bearing multi-TTF units show good electron-donating properties and are found to contain four different octa- radical cationic TTF moieties.

In the present work, we describe the synthesis and photophysical and electrochemical properties of two new norphthalocyanine (NPc) derivatives 6 and 7, composed of one TTF units acting as an electron donor and a single norphthalocyanine ring acting as an acceptor and covalently linked with one thiacrown ether spacers.

The reaction pathways for the preparation of the complexes were shown in Scheme 1. Compound $\mathbf{1}$ was obtained according to a published procedure ${ }^{19}$ and then deprotected by treatment with cesium hydroxide in a mixture of DMF and $\mathrm{MeOH}$ after which the resulting thiolate ion was 
reacted with excess 2-bromoethanol to give $\mathbf{2}$ in 59\% yield. Tosylation of $\mathbf{2}$ formed $\mathbf{3}$, and the latter was converted to the bis-iodo intermediate 4 by a Finkelstein reaction using sodium iodide in acetone. Subsequently, compound $\mathbf{4}$ was reacted with an equivalent amount of cis-1,2-dicyano-1,2-ethylenedithiolate disodium salt in DMF and under nitrogen to give the TTF-dicyano-tetrathiacrown ether 5 in good yield (40.5\%). The relatively high yields of the cyclization reaction can be attributed to the effect of being high dilution. ${ }^{12}$ The IR spectrum of $\mathbf{5}$ showed a typical $\mathrm{C} \equiv \mathrm{N}$ stretching vibration at $2215 \mathrm{~cm}^{-1}$ that disappeared upon tetramerization to the norphthalocyanine 6. The mixed condensation of 1 equiv. of dithiomaleonitrile 5 (A) and 20 equiv. of phthalonitrile (B) under classic Linstead macrocyclization conditions (magnesium n-Butoxide/n-Butanol) produced two porphyrinic products; the desired norphthalocyanine $6\left(\mathrm{AB}_{3}\right)$ and the phthalocyanine $\left(\mathrm{B}_{4}\right)$. Fortunately, the significant difference in polarity between the products allowed us to readily separate product $\mathbf{6}$. Demetallation of $\mathbf{6}$ with acetic acid gave the free base norphthalocyanine 7 in $66 \%$ yield as a deep blue powder. Compound 6 and 7 were soluble in the usual organic solvents with the exception of alcohols. The ${ }^{1} \mathrm{H}$-NMR spectra of 6 and 7 were recorded in $\mathrm{CDCl}_{3}$ at $25^{\circ} \mathrm{C}$ showed slightly broadened signals except for those originating from the terminal methyl groups. This could be explained as the result of aggregation in concentrated solutions. ${ }^{20}$ In the ${ }^{1} \mathrm{H}$ NMR spectrum of $\mathbf{7}$, the typical shielding of the inner core NH protons was observed as broad signals at $\delta=-1.79$. The matrix assisted laser desorption/ionization - time of flight (MALDI-TOF) masss pectra of 6 and 7 featured peaks at $\mathrm{m} / \mathrm{z}$ values of $1103.11[\mathrm{M}]^{+}$and 1081.47 $[\mathrm{M}]^{+}$, respectively, corresponding to the $\mathrm{M}^{+}$of $\mathbf{6}$ and 7 (1103.11 and 1081.62). Elemental analyses of these compounds were in accord with the proposed molecular formula. 

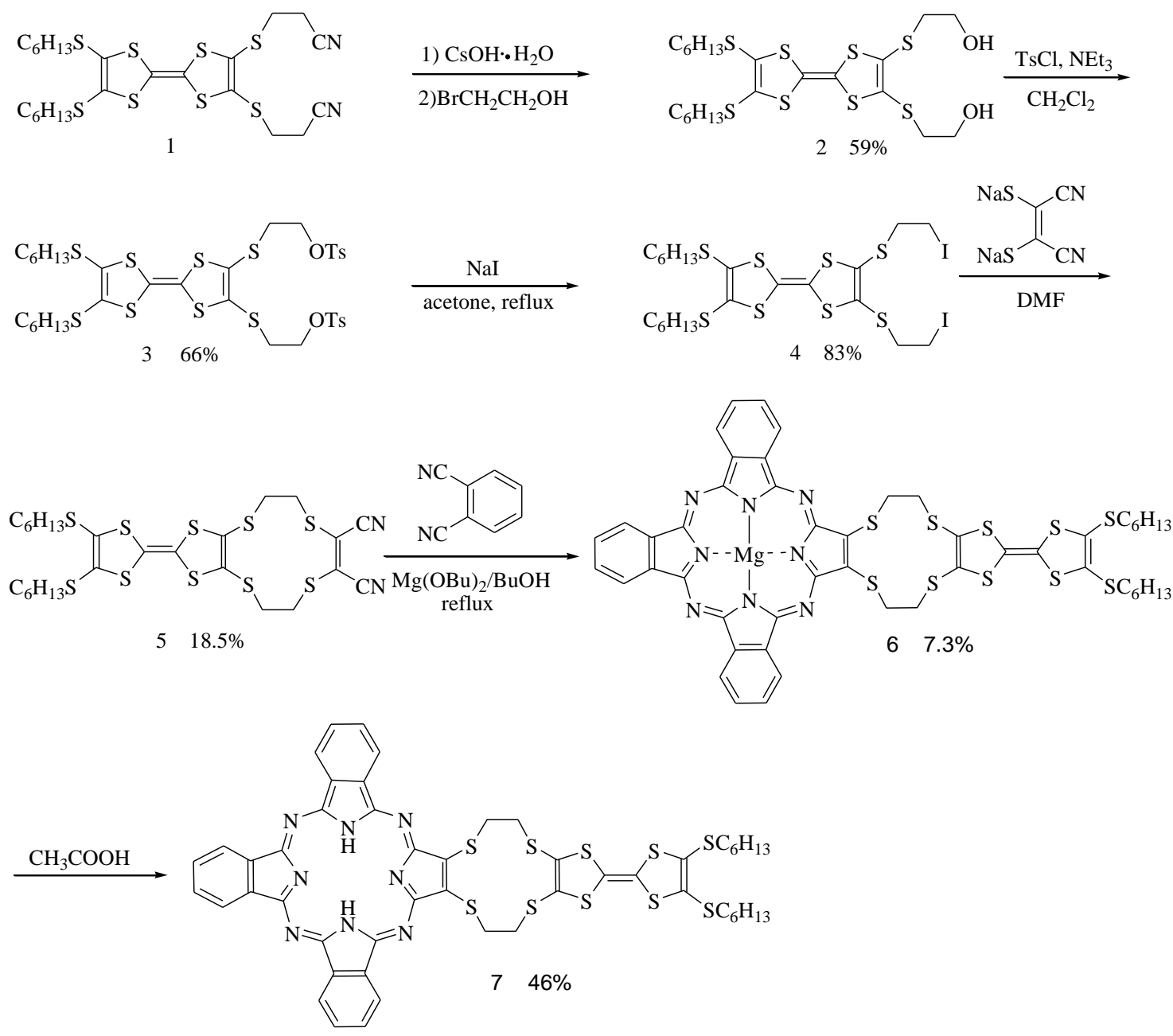

Scheme 1. Synthetic route to norporphyrazines (6 and 7)

The optical spectra of all norphthalocyanine exhibited two main bands, a Soret or B band ( $\pi \rightarrow \pi^{*}$, corresponding to a deep $\pi \rightarrow$ LUMO transition) between 339-359 nm and another at approximately $650 \mathrm{~nm}$, denoted as the $\mathrm{Q}$ band $\left(\pi \rightarrow \pi^{*}\right)$ (Figure 1). In general, the four fold symmetric porphyrinic macrocycles all generate similar optical spectra, with single transitions for both the Q and B bands. In contrast, the optical spectra of the unsymmetrical norphthalocyanines 6 and 7, with three fused benzo rings and one TTF units substituted with a thiacrown ether moiety, clearly showed a splitting of the Q band. These optical spectra resemble those reported in the literatures for norphthalocyanines substituted with 2,3-dialkylthio groups in the literatures. ${ }^{20}$ These differences can be explained using Gouterman's highly simplified four orbital model for the optical 
spectra of porphyrinic macrocycles.

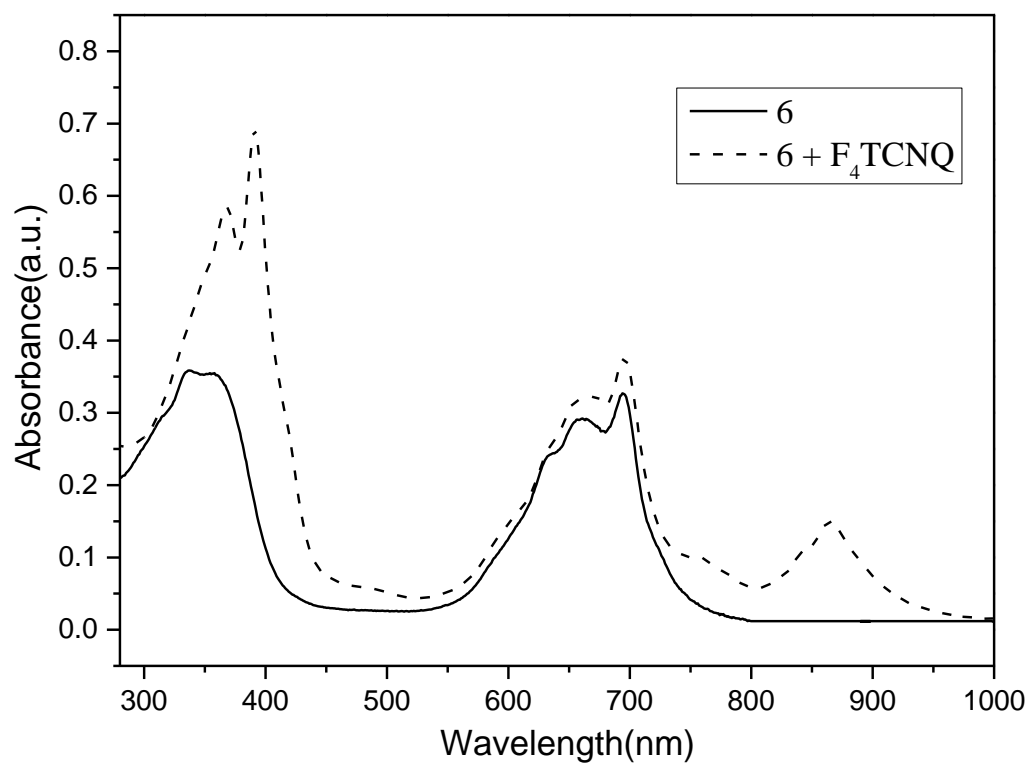

Figure 1. Absorption spectra of 6 in $\mathrm{CH}_{2} \mathrm{Cl}_{2}\left(1 \times 10^{-5} \mathrm{M}\right)$ after addition of 1 equiv F4TCNQ.

To further assess the electron-donating properties of the target compounds $\mathbf{6}$ was doped with an excess of 7,7,8,8-Tetracyanoquinodimethane (TCNQ) in $\mathrm{CH}_{2} \mathrm{Cl}_{2}$. However, no charge transfer band was observed in the 740 to $1000 \mathrm{~nm}$ region, which might be attributed to the presence of the electron-withdrawing NPc ring. In contrast, the addition of one equiv. of 2,3,5,6-Tetrafluoro-7,7,8,8-tetracyanoquinodimethane ( $\left.\mathrm{F}_{4} \mathrm{TCNQ}\right)$ to a $\mathrm{CH}_{2} \mathrm{Cl}_{2}$ solution of $\mathbf{6}\left(1 \times 10^{-5}\right.$ M) resulted in the appearance of two new charge transfer absorption bands, centered at $\lambda_{\max }$ of $760 \mathrm{~nm}$ and $\lambda_{\max } 863 \mathrm{~nm}$ in the UV-Vis spectrum (Figure 1). These new bands corresponded to the SOMO-LUMO transition of the cation radical species of the TTF moieties. ${ }^{17}$ The formation of the $\mathrm{F}_{4} \mathrm{TCNQ}^{-} / \mathrm{TTF}^{+}$charge transfer complex in $\mathrm{CH}_{2} \mathrm{Cl}_{2}$ was also confirmed from FT-IR and electron paramagnetic resonance (EPR) spectra. The FT-IR spectrum of $\mathbf{6}$ showed the nitrile stretch of the $\mathrm{F}_{4}$ TCNQ radical anion at $2191 \mathrm{~cm}^{-1}$ compared with the band at $2222 \mathrm{~cm}^{-1}$ generated in the neutral state. In addition, the EPR spectrum of $\mathbf{6}$ was centered in the vicinities of $g=2.008$ and 2.002 regions that were characteristic of both a TTF radical cation and a F $_{4}$ TCNQ radical anion. ${ }^{17}$ These 
results demonstrated that some charge transfer took place between the TTF unit(s) and $\mathrm{F}_{4} \mathrm{TCNQ}$ in solution(Figure 2).

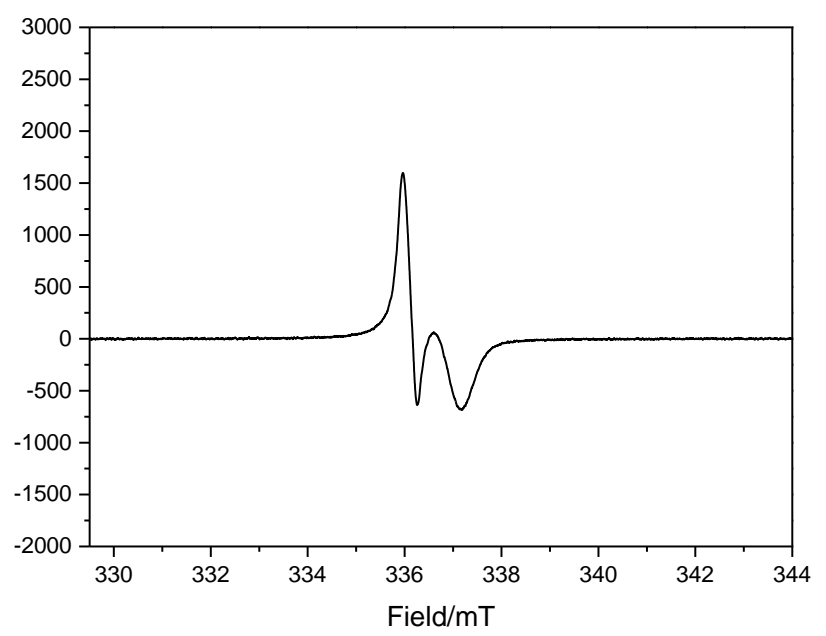

Figure 2. EPR spectrum of the complex of 6 with $\mathrm{F}_{4} \mathrm{TCNQ}$ in $\mathrm{CH}_{2} \mathrm{Cl}_{2}$ at $25^{\circ} \mathrm{C}$.

The electrochemical characterization of compounds 6 and 7 was carried out using cyclic voltammetry in a mixture of $\mathrm{CH}_{2} \mathrm{Cl}_{2}$ and $\mathrm{CH}_{3} \mathrm{CN}(7: 3$, v/v). Figure 3 presented the cyclic and differential pulse voltammograms of $\mathbf{6}$ within a $-2 \mathrm{~V}$ to $+2 \mathrm{~V}$ potential window. Compound $\mathbf{6}$ generated two reduction couples $\left(\mathrm{E}_{1 / 2}=-1.42\right.$ and $\left.-0.95 \mathrm{~V}\right)$ and three oxidation couples $\left(\mathrm{E}_{1 / 2}=0.47\right.$, 0.93 and $1.59 \mathrm{~V}$ ) within the potential window of the $\mathrm{DMC}-\mathrm{ACN} / \mathrm{Bu}_{4} \mathrm{NPF}_{6}$ electrolyte system. These five couples were assigned to $\mathrm{NPc}^{-3} / \mathrm{NPc}^{-4}$ (I), $\mathrm{NPc}^{-2} / \mathrm{NPc}^{-3}$ (II), $\mathrm{TTF}^{+} / \mathrm{TTF}$ (III), $\mathrm{TTF}^{+2} / \mathrm{TTF}^{+\cdot}$ (IV) and $\mathrm{NPc}^{-1} / \mathrm{NPc}^{-2}(\mathrm{~V})$ on the basis of results previously published in the literature. ${ }^{19}$ Processes I, II and $\mathrm{V}$ were irreversible in terms of the ratio of anodic to cathodic peak currents. In contrast, processes III and IV, which can be assigned to the simultaneous first and second oxidations of the TTF unit, were quasi-reversible. These latter two processes have anodic to cathodic peak separation $(\triangle \mathrm{E})$ values of $0.183 \mathrm{~V}$ and $0.21 \mathrm{~V}$, respectively, and the unity of the $\mathrm{I}_{\mathrm{pa}} / \mathrm{I}_{\mathrm{pc}}$ ratios of unity at all scan rates and linear variation of the peak currents. Compound $\mathbf{7}$ showed similar voltammetric behaviors to $\mathbf{6}$, accompanied by significant anodic shifts of the two reduction waves, corresponding 
to the demetallation of the magnesium complex 6 (Figure S8).

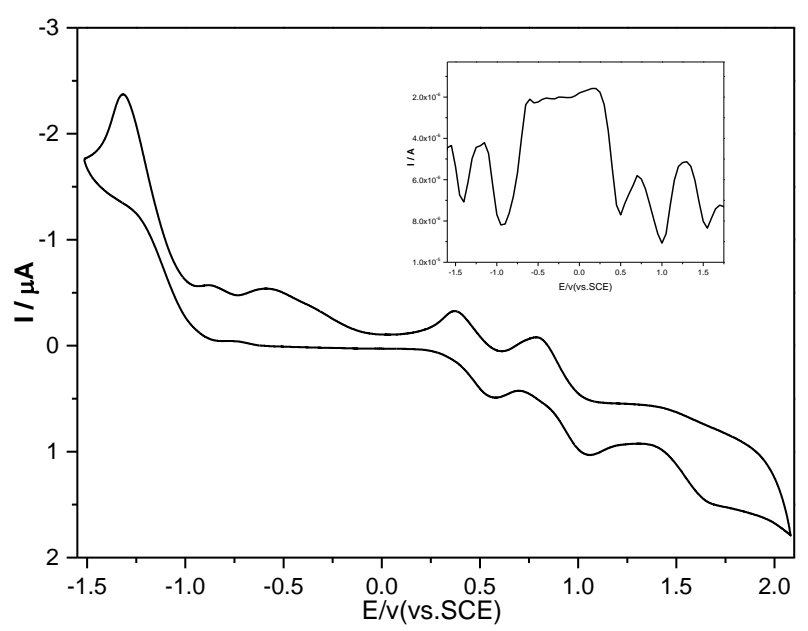

Figure 3. Cyclic voltammogram of $6\left(1 \times 10^{-3} \mathrm{M}\right)$ in $0.1 \mathrm{M}$ tetrabutylammonium hexafluorophosphate in a mixture of $\mathrm{CH}_{2} \mathrm{Cl}_{2} / \mathrm{MeCN}(9: 1, \mathrm{v} / \mathrm{v})$ at $0.1 \mathrm{~V} \mathrm{~s}^{-1}$ (inset: DPV of 6 under the same conditions).

To investigate the nature of the electronic transitions, we performed molecular orbital calculations for 6 at the Perdew-Burke-Erzenrhof (PBE) functional level ${ }^{22}$ and the basis set effect has been tested using different combination of basis sets for metal and main group atoms. LANL2DZ ${ }^{23}$ and $6-31 \mathrm{G}^{24}$ basis sets were used for $\mathrm{Mg}$ and the other atoms in all calculations, respectively. All calculations were performed with the B.01 revision of the Gaussian 09 program package. ${ }^{25}$ Figure 3 showed the HOMO and LUMO levels of $\mathbf{6}$. It is evident that the HOMO and LUMO of 6 are significantly different. The electron density distributions of the HOMO are primarily situated on sulfur atoms in dihexyl and TTF moieties, while the LUMO density is mainly concentrated on the Mg norporphyrazines. Generally, dye molecule with this type of electron distribution exhibit the intermolecular charge transfer (ICT) characteristic (Figure 4). ${ }^{26}$ 

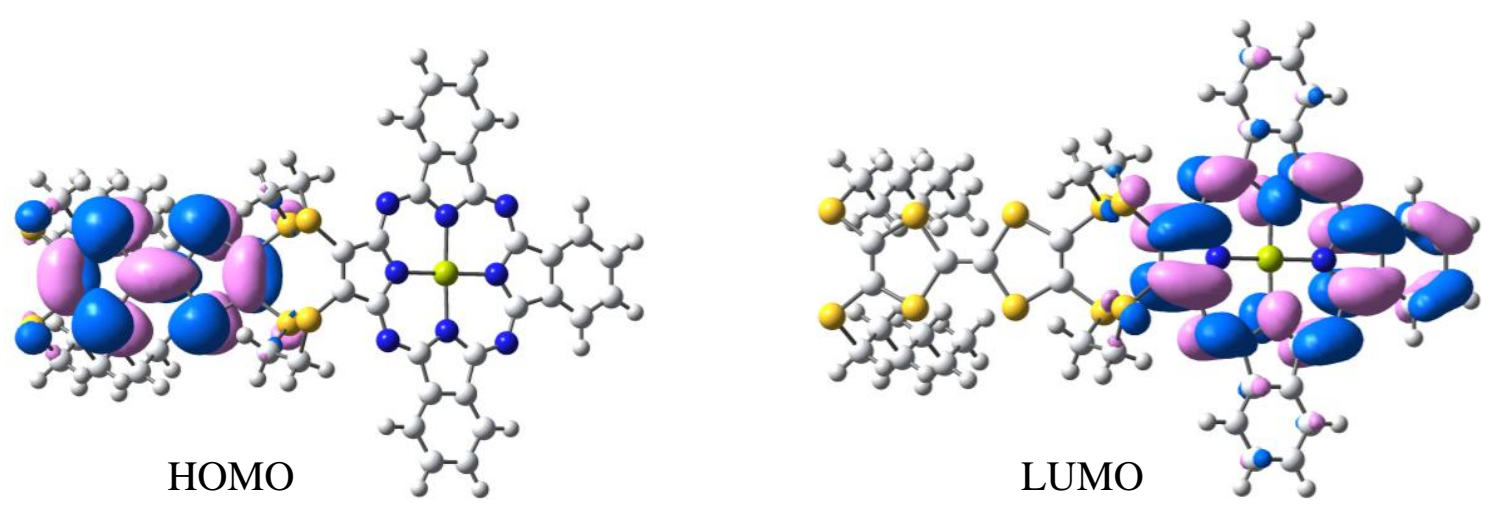

Figure 4. A diagram showing the HOMO and LUMO levels of compound 6.

In summary, we first synthesized two $\mathrm{A}_{3} \mathrm{~B}$-type norphthalocyanines ( 6 and 7 ) each bearing a single TTF unit linked by a thiacrownetherspacer. These syntheses were confirmed using NMR spectroscopy, MALDI-TOF mass spectrometry and elemental analysis. The ability of compound $\mathbf{6}$ to function as a donor for $\mathrm{F}_{4}$ TCNQ was established, and evidence for the formation of a charge transfer complex was obtained by UV-vis, EPR and IR spectroscopy. Theoretical calculations were found to be useful as a means of improving our understanding of the electronicstructures of the interacting molecules. The complexation of the target compounds with soft metal cations and the synthesis of long alkyl chain analogs are currently being investigated in our laboratory.

\section{Acknowledgements}

This work was supported by the National Science Foundation of China (No. 21442004), the National Natural Science Foundation of Jilin Province (grant No. 20101548). 


\section{References}

1. Gu, P.; Zhang, Y.; Liu, G.; Ge, J.; Xu, Q.; Zhang, Q.; Lu, J. Chem.-Asian. J. 2013, 8, 2161.

2. Zhang, G. F.; Aldred, M. P.; Gong, W. L.; Li, C.; Zhu, M. Q. Chem. Commun. 2012, 48, 7711.

3. Zhang, G.; Zhang, D.; Zhou, Y.; Zhu, D. J. Org. Chem. 2006, 71, 3970.

4. Lei, Z., Ali, H. Y., Zhao, Y., Ronald, J. C. Journal of Photochemistry and Photobiology A:

Chemistry, 2015, 311, 1.

5. Lei, Z., Zhao, Y., J. T. S., Kesavapillai, S. RSC Adv., 2014, 4, 20398.

6. Bergkamp, J. J., Decurtins, S., Liu, S. Chem. Soc. Rev., 2015, 44, 863.

7. Zhao,Y., Liang, F. Current Organic Chemistry, 2014, 18, 2016.

8. Wan, Z.; Jia, C.; Zhang, J.; Yao, X.; Shi, Y. Dyes Pigm. 2012, 931456.

9. Loosli, C.; Jia, C.; Liu, S. X.; Haas, M.; Dias, M.; Levillain, E.; Neels, A.; Labat, G.;

Hauser, A.; Decurtins, S.; J. Org. Chem. 2005, 70, 4988.

10. Hou, R.; Qiu, H.; Chen, T.; Yin , B. Heterocycles. 2009, 78, 1799.

11. Bonnet, R. Chem. Soc. Rev. 1995, 24, 19.

12. Leng, F.; Hou, R.; Jin, L.; Yin, B.; Xiong, R. G. J. Porphyrins Phthalocyanines. 2010, 14, 108.

13. Hou, R.; Li, B.; Zhong, K.; Li, H.; Jin, L. Y.; Yin, B. Eur. J. Org. Chem. 2012, 1138.

14. Zhao, M.; Zhong, C.; Stern, C.; Barrett, A. G. M.; Hoffman, B. M. J. Am. Chem. Soc. 2005, 127, 9769.

15. Fukuda, T.; Sato, J.; Hashimoto, N.; Kobayashi, N. Chem. Commun., 2014, 50, 14269.

16. Michel, S. L. J.; Goldberg, D. P.; Stern, C.; Barrett, A. G. M.; Hoffman, B. M. J. Am. Chem. Soc. $2001,123,4741$.

17. Leng, F.; Wang, X.; Jin, L.; Yin, B. Dyes Pigm. 2010, 87, 89.

18. Hou, R.; Jiang, C.; Chen, T.; Jin, L. Yi.; Yin, B. Heterocycles. 2011, 83, 1859. 
19. Lau, J.; Becher, J. Synthesis. 1997, 1015.

20. Lange, S. J.; Sibert, J. W.; Barrettc, A. G. M.; Hoffman, B. M. Tetrahedron. 2000, 56, 7371.

21. Sly, J.; Kasák, P.; Gomar-Nadal, E.; Rovira, C.; Górriz, L.; Thordarson, P.; Amabilino, D. B.;

Rowan, A. E.; Nolte, R.J.M. Chem. Commun. 2005, 10, 125.

22. Perdew, J. P.; Burke, K.; Ernzerhof, M. Phys. Rev. Lett., 1996, 77, 3865.

23. Hay, P. J.; Wadt, W. R. J. Chem. Phys. 1985, 82, 299.

24. Hariharan,P.C.; Pople, J.A. Mol. Phys. 1974, 27, 209.

25. Frish ,M.J.; et al. Gaussian 09, Gaussian Inc., Wallingford, CT, 2009.

26. Shang, X.; Han, D.; Zhan, Q.; Zhou, D.; Zhang, G. New Journal of Chemistry. 2015, 39, 2588. 


\section{Graphical Abstract}
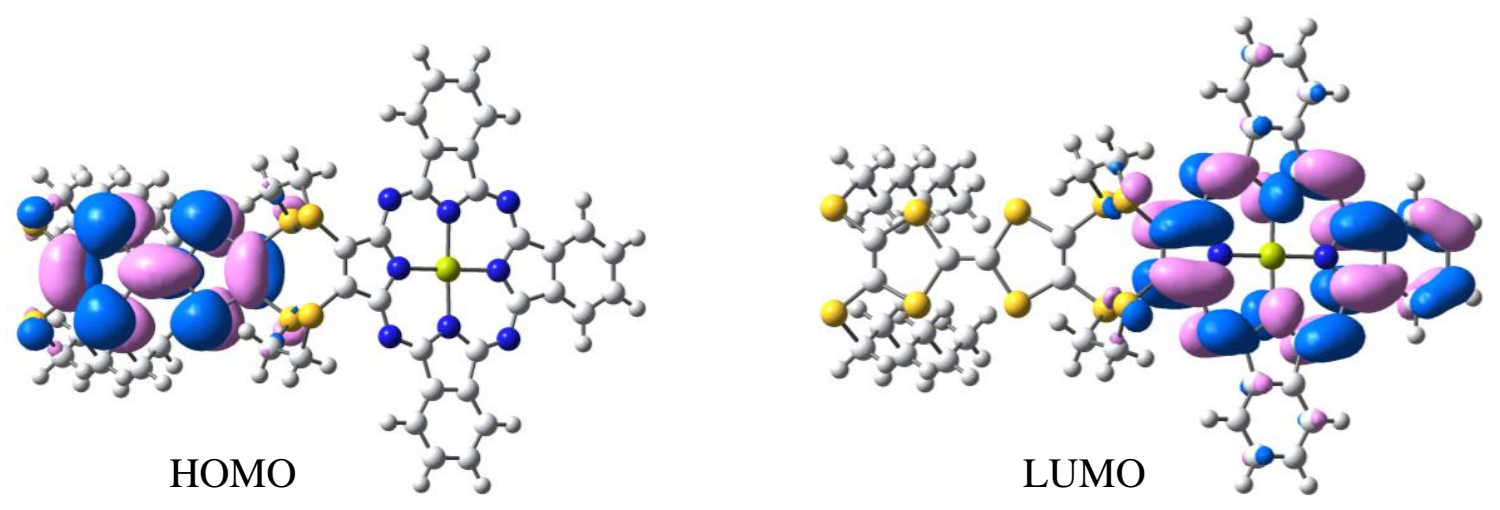